\title{
Heidegger, Deleuze y la diferencia. Aportes para pensar la irrupción de la novedad
}

\section{Heidegger, Deleuze and Difference. Contributions to think the emergence of the Event}

\author{
Juan Pablo Esperón \\ Investigador CONICET. Buenos Aires, Argentina. \\ jpesperon@conicet.gov.ar
}

\section{Resumen}

Este artículo busca plantear los problemas en torno a la noción de diferencia a partir de las filosofías de Heidegger y Deleuze, dos de los pensadores que, a nuestro entender, han marcado el debate sobre esta cuestión en nuestra época. ¿Qué tienen de "nuevo" estos modos de pensar propuestos por Heidegger y Deleuze sobre la noción de la diferencia?, ¿qué encuentros se suscitan entre Heidegger y Deleuze?, ¿qué desacuerdos se producen entre sus propuestas de pensamiento? El desarrollo del artículo intenta responder críticamente a estas preguntas.

Palabras clave: diferencia, acontecimiento, ontología, Gilles Deleuze, Martin Heidegger.

\section{Abstract}

This article seeks to raise the problems of the notion of difference according to Heidegger and Deleuze, for, to our knowledge, they are two of the mayor contemporary thinkers who have influenced our time by addressing this issue. What is "new" about the ways Heidegger and Deleuze think the notion of difference? What convergences appear between their proposals? What disagreements occur between their philosophies? The article is an attempt to provide critical answers to these questions.

Keywords: Difference, Event, Ontology, Gilles Deleuze, Martin Heidegger. 


\section{Planteo del problema}

En la nota 21 del primer capítulo de Diferencia y repetición, su gran obra ontológica, Deleuze sostiene que la metafísica es impotente para pensar la diferencia en cuanto tal, dado que la representación subordina la diferencia a la identidad, pues en la diferencia no hay síntesis, ni mediación, ni reconciliación al modo dialéctico. Por su parte, en su conferencia de 1957 titulada "El principio de identidad", Heidegger afirma que tal principio refiere a que "todo ente es idéntico a sí mismo". Su fórmula usual es expresada de la siguiente manera: $\mathrm{A}$ = A. Este principio es considerado la suprema ley lógica para el pensamiento occidental, pues la tradición filosófica convirtió en principio de identidad los principios aristotélicos de no contradicción y del tercero excluido $^{1}$. Ambos principios fueron asociados a la frase en que Parménides señala la mismidad entre ser y pensar, a saber, "ser y pensar son lo mismo"; pero to autó, lo mismo, se comprende, en la tradición metafísica occidental, como igualdad lógica y unidad óntica, y no como mismidad.

A su vez, el filósofo alemán aclara que, al identificar al ser del ente en cuanto tal como fundamento de cada ente, como lo fundado, se olvida al ser mismo en cuanto a su diferencia ontológica originaria. Pero el ser fundamento que funda no es el ser, en su estatus de diferencia-diferenciante, con lo ente. En este sentido, Heidegger aporta elementos importantísimos para la problematización y comprensión de la diferencia de un modo alternativo al de la metafísica entendida como onto-teo-logía. Sin embargo, Deleuze argumenta que esta problematización de la diferencia queda a mitad de camino, porque para Heidegger el significado propio de "lo mismo" en la sentencia de Parménides es comprendido como aquello que reúne lo diferente en una unión original; entonces Deleuze se pregunta ¿es suficiente oponer "lo mismo" a "lo idéntico" para pensar la diferencia en cuanto tal y arrancarla de las mediaciones? Deleuze sostiene que en la filosofía heideggeriana no se da una verdadera superación de las estructuras metafísicas para poder pensar la diferencia en cuanto diferencia, dado que Heidegger, en última instancia, sigue pensando al ser como arkhé, como fundamento de lo ente. Entonces, cabe preguntarse junto a Deleuze: ¿Heidegger realmente concibe al ser sustraído de toda subordinación con respecto a la identidad de la representación? Deleuze observa claramente que el intento heideggeriano por pensar la diferencia no llega a buen puerto porque, al poner la diferencia en tensión con la mismidad, aquella termina reducida a esta, i.e., la diferencia resulta pensada sobre "lo mismo". Ello sugiere seguir pensando la realidad a partir de un fundamento último y organizador cuyo soporte es, en este caso, la mismidad.

1 El principio de identidad no lo formula Aristóteles, pero el filósofo griego supone la autoidentidad de cada ente consigo mismo; sobre todo en la formulación canónica del principio de no contradicción. Estamos hablando, naturalmente, del principio de identidad de la llamada "lógica de predicados", esto es, $(\mathrm{x})(\mathrm{x}=\mathrm{x})$, donde $\mathrm{x}$ es una variable de individuo. Igualmente, esto no está formulado de este modo en Aristóteles; y menos aun aparece formulado en el corpus que una proposición es idéntica a otra proposición $(\mathrm{A}=\mathrm{A})$, donde la letra A es una variable proposicional. 
Deleuze muestra que en la filosofía de Heidegger la tensión entre la identidad y la diferencia se juega sobre "lo mismo". Por su parte, interpretando la filosofía de Nietzsche y repensando el eterno retorno, observa Deleuze que la diferencia ya no ha de pensarse sobre "lo mismo" -lo que implicaría seguir atrapado dentro de un modo de pensamiento único y consumado-, sino que replantear de un nuevo modo el problema de la diferencia en cuanto tal implica pensarla en tensión con la repetición, entendida como repetición no de "lo mismo", sino repetición de la diferencia. Para Deleuze, si lo que retorna es la diferencia, esto implica que no hay idea, ni unidad fundamental, ni identidades de antemano. El eterno retorno es la potencia del ser del devenir que acontece en su absoluta y radical contingencia. En definitiva, lo que retorna es siempre lo que difiere. No hay sujeto o substrato que subyazca al volver. Tampoco es la diferencia la que regresa como un soporte del movimiento conservándose a sí misma, porque la diferencia no deja de afirmarse, reproducirse y repetirse como siendo siempre otra; entonces, no hay mismidad ni identidad en donde pueda apoyarse. Volver es, para Deleuze, el ser de la diferencia, y lo que vuelve y se repite es la condición de posibilidad de todo ente en su dimensión intensiva; por eso la diferencia es diferenciante, es decir, produce las diferencias activamente. Así, el eterno retorno es y se dice de la diferencia en cuanto a su intensidad, lo que hace que el retorno no sea de lo mismo o igual, sino que siempre sea de lo diferente. De aquí se infiere el sentido unívoco que Deleuze le confiere al ser. "Las diferencias vuelven, el ser es el volver de las diferencias, sin que haya diferencias en su manera de volver y decir el ser" (Mengue 266). Esto significa que no es el ser el que vuelve y subyace a las diferencias que distribuye. El substrato del volver no es el ser; son las diferencias, y de estas, el hecho de que retornan de lo que se dice que son, de las que se dice que "vuelven" en un solo y mismo sentido.

Por último, debemos preguntarnos también: ¿Deleuze realmente ha comprendido la filosofía de Heidegger? ¿No es la noción de Ereignis (acontecimiento apropiante), en el pensamiento de Heidegger, un modo de problematización de la diferencia que no puede ser reducida a la identidad? Por otro lado, debemos preguntarnos también en torno al planteo deleuziano: ¿las nociones de repetición, intensidad, inmanencia, fuerza, etc., acaso no son subsidiarias de un tipo de pensamiento metafísico que se juega sobre la base de la representación que supone al principio de identidad, y que impide pensar la diferencia en sí misma?

Este artículo intenta responder a tres interrogantes: ¿qué tiene de "nuevo" este modo de pensar propuesto por Heidegger y Deleuze en torno a la noción de diferencia?, ¿qué encuentros se suscitan entre Heidegger y Deleuze?, ¿qué desacuerdos se producen entre sus propuestas de pensamiento? Por todo lo expuesto, resulta de suma relevancia para la filosofía actual preguntarse qué es y por qué hay diferencia, y de este modo, poder aprehender qué implicancias conlleva esta noción para la compresión de la novedad que en su carácter contingente se nos presenta y nos afecta. 


\section{El problema de la diferencia en el planteo heideggeriano}

Para Heidegger, la filosofía es aquel pensar propio de Occidente que busca determinar al ente en su ser. Su punto de partida está en los entes mismos, en lo finito, en lo limitado, en las cosas. El ser-humano, en cuanto ser mortal, está entre medio de ellas y tropieza con ellas en las dimensiones propias de su existencia: el espacio y el tiempo, lo que implica la apertura del mundo como mundo. Así, la filosofía se constituye como tal, al configurar un modo propio de preguntar sobre los entes. Entonces, por un lado, la cuestión fundamental inherente a esta actividad es: ¿qué es el ser del ente?, esto es: preguntarse por el ente en cuanto tal, es decir, qué es en general lo que mienta al ente en cuanto ente. Esta pregunta apunta a la estructura ontológica de todo ente. Por otro lado, la filosofía se cuestiona: ¿por qué es el ente y no más bien la nada? Esta pregunta resalta el carácter contingente de todo ente mundano; pero, equívocamente, a lo largo de la historia occidental se ha asociado la respuesta a dicha pregunta con el ente superior a partir del cual todo surge y del que todo depende. Esta interrogación se refiere a la estructura teo-lógica del ente supremo. Por ello es que para Heidegger la filosofía y, más específicamente, la metafísica occidental se ha constituido en íntima unión ontoteológica. Ahora bien, este esquema o estructura que define a la metafísica ontoteológicamente no puede ser atribuido absolutamente ni a Platón ni a Aristóteles: aunque Heidegger afirme que en Aristóteles la metafísica se constituyó como tal, numerosos estudios han demostrado que ello es insostenible. Sin embargo, podemos afirmar que el discurso metafísico que aquí está en cuestión, para Heidegger, se ha afianzado de tal modo conforme a la tradición medieval, a la asimilación y apropiación de la filosofía griega por el mundo cristiano y, fundamentalmente, a las discusiones escolásticas y a la relectura de Aristóteles en clave teológica.

Entonces, la metafísica es aquella disciplina que teoriza sobre el ente en cuanto ente, en busca de su estructura general -ontología- y de la teoría del ente supremo del cual dependen todos los demás entes -teología-. La doble configuración de la metafísica como ontoteología presenta conexiones que no han sido problematizadas en sus raíces comunes. Cuestionarlas equivale a pensar lo impensado ${ }^{2}$ en la metafísica, esto implica, de algún modo, estar fuera de ella. Heidegger llama "historia de la metafísica" a la forma de pensar que desde Platón a Nietzsche se despliega como teoría general del ser del ente y como teoría del ente supremo (ontoteología), dado que se ha olvidado al ser mismo y su diferencia con el ente, a favor del ser como fundamento del ente. Ahora bien, en este punto aparece un extravío o enlace equívoco, porque se identifica al ser

2 Lo no-pensado no se refiere a todo aquello que la filosofía dejó de pensar o a los temas que quedaron marginados de la reflexión y del pensar conceptual, sino más bien a lo que aparece como olvidado en la historia de la metafísica, pero que, precisamente, por aparecer así, ha dado lugar a la misma metafísica. Lo impensado no fue olvidado al principio de esa historia, y por eso no es algo que hubiera que recuperar, sino que es lo que está presente en cada pensador en el modo de la ausencia. 
con aquel ente que fundamenta y causa toda existencia ${ }^{3}$. Tal identificación es la que hace posible, a la vez, pensar al ser como fundamento. Pero al identificar al ser como fundamento de lo ente se olvida la diferencia en cuanto tal, esto es, la diferencia entre ser y ente (Esperón 35). Aceptado esto, se abre el camino para que el ente supremo, a través de la concatenación entre causas y efectos, se constituya en fundamento y, a la vez, en causa primera de todo lo existente. Ello constituye, para Heidegger, el olvido de la diferencia y la imposibilidad de pensar la irrupción de la novedad en cuanto tal, pues lo nuevo siempre es explicado y atribuido a un ente superior o fundamentado por un ente supremo que funciona como centro organizador, garante de la existencia de todo ente y dador de sentido, conforme al modo de pensar ontoteológico explicitado aquí.

Los problemas en torno a la diferencia se desarrollan a lo largo de toda la obra de Heidegger. Allí estos problemas son puestos en primer plano y problematizados. En Ser y Tiempo, quizás su gran obra, Heidegger elabora un plan de delimitación de la ontología metafísica. Parte de una insuficiencia sobre la noción de ser, transmitida por tal historia de la metafísica, para comprender "lo que es" y al hombre mismo. Pero a su vez, es él mismo quien pregunta por el sentido del ser y cuestiona la noción de ser transmitida por la metafísica. Como es sabido, también, Sein und Zeit se encamina a señalar al tiempo como horizonte de la pregunta por el sentido del ser como acontecimiento apropiante (Ereignis), llegando a la indicación de que el ser se da dentro del horizonte del tiempo, en el sentido que es el instituirse mismo de la temporalidad como unidad de los tres éxtasis: pasado, presente y futuro. Esta problemática del ser, de la que no puede darse una definición, es la base de la diferencia y, a su vez, este problema ya es el de Ser y Tiempo, porque al plantearse el interrogante por el sentido del ser se evidencia su diferencia con los entes. Con todo, la teorización de la diferencia como resultado del planteo de Ser y Tiempo se encuentra en un ensayo posterior, de 1929, llamado "La esencia del fundamento". En él, Heidegger afirma:

El no ser escondido del ser significa siempre la verdad del ser del ente, sea este real o no. Recíprocamente, en el no ser escondido de un ente está siempre implícita la verdad de su ser. La verdad óntica y la verdad ontológica se refieren, respectivamente, al ente en su ser y al ser del ente. Ellas se compenetran esencialmente en base a su relación con la diferencia (Unterscheid) entre el ser y el ente (ontologische Differenz). La esencia de la verdad -que por eso se bifurca necesariamente en óntica y ontológica-, sólo es posible, junto al abrirse de esta diferencia (126).

Aquí la diferencia se da entre lo que aparece en un cierto horizonte y el horizonte mismo como apertura que posibilita la aparición del ente. Ahora bien, Heidegger muestra que en la exégesis historiográfica la pregunta por la diferencia (ontológica) resulta

3 Tal identificación es posible porque está supuesta y opera la lógica de la identidad que Heidegger muestra claramente en su conferencia "El principio de Identidad". 
extraviada u olvidada, pues se ha reducido todo ente intramundano a la objetividad de la presencia, ello es, al concepto, posibilitando su control y manipulación a través del dominio tecnocientífico. A pesar de ello, en el fondo de esta cuestión emerge el problema radical de la filosofía, la pregunta por el carácter eminentemente contingente de la realidad: ¿por qué hay diferencia? Lo anterior lleva a Heidegger a replantear el problema de la diferencia fuera de los límites de las estructuras categóricas de la metafísica entendida como ontoteología.

Para diferenciarse de esa tradición -la ontoteológica-, Heidegger intenta pensar la noción de diferencia ontológica (ontologische Differenz), según la cual hay que comprender al ser del ente como genitivo ${ }^{4}$ objetivo $^{5}$ y genitivo subjetivo ${ }^{6}$ a la vez. Aquí está implícita siempre la diferencia (Unterscheidung) ${ }^{7}$ en cuanto tal. Ambos, ser y ente, están vinculados, mutuamente se pertenecen. En el primer caso, se indica que el ser pertenece a lo ente, y en el segundo caso se indica que lo ente pertenece al ser mismo. Así, se convierte en asunto del pensar a la diferencia en cuanto tal, es decir, en cuanto "diferenciante". El participio presente indica la donación del ser respecto a lo ente. Es fundamental comprender al "es", en el lenguaje, como un tránsito a... El ser sobreviene en el ente y lo desoculta, pero a su vez el ser se oculta en aquello que desoculta. Esta trascendencia del ser, como sobrepasamiento y donación en lo ente al que llega, ad-viene. Este es el sentido propio del participio presente, pues nombra la tensión que se "da" entre (Zwischen) ser y ente. Así, Heidegger puede afirmar que "sobrevenida y llegada están a la vez separadas una de otra y referida la una a la otra" (Identidad y Diferencia 141).

Asimismo, para Heidegger la noción de diferencia está íntimamente ligada a la de mismidad enunciada por Parménides: "ser y pensar son lo mismo". La mismidad de pensar y ser es comprendida por el filósofo alemán como mutua pertenencia (Zusammengehören $)^{8}$ entre (Zwischen) ambos. Esta identidad originaria que sale fuera de la representación de la metafísica mienta una "mismidad" a partir de la cual ser y pensar se pertenecen mutuamente. ¿Qué se entiende, pues, por mismidad? La mutua pertenencia entre ser y pensar (68-73). Pero ¿ser y pensar no son dispares? El hombre no es simplemente un ser racional -con esta determinación la metafísica lo convirtió en un ente-. El ser-humano9 es, en cuanto tal, pertenencia al ser que resulta mutua

\footnotetext{
4 El genitivo indica posesión o pertenencia.

El ser es en tránsito a..., recae sobre lo ente.

Se acentúa el ser mismo en su sobre-llegar a lo ente.

7 Inter-cisión. Es la es-cisión entre (del latín inter) ser y ente, que resulta inter porque a su vez están referidos el uno al otro. "La diferencia de ser y ente, en tanto que inter-cisión entre la sobrevenida y la llegada, es la resolución desencubridora y encubridora de ambas. En la resolución (Austrag) reina el claro (Lichtung) de lo que se cierra velándose y da lugar a la separación y la reunión de la sobrevenida y la llegada" (Identidad y Diferencia 141).

8 Heidegger dice que el pertenecer (ge-horen) determina lo mutuo (zusammen), y no viceversa (68-73).

9 En la noción ser-humano se devela la relación presente entre (zwischen) ser y hombre, del mismo modo que se señala la íntima relación entre la identidad y la diferencia. La identidad, mismidad entre ser y hombre, es en la diferencia-diferenciante (Unterscheidung).
} 
porque el ser pertenece, asimismo, al hombre, ya que solo así "es", acontece. No hay preeminencia de uno sobre el otro; hay una vinculación respetando cada uno su lugar en su mutua pertenencia pero, a su vez, en su diferencia originaria (68-73). De este modo, según la comprensión heideggeriana desde el pensar fundante o desde otro modo de pensar, la frase de Parménides dice "el ser tiene su lugar-con el pensar-en lo mismo" (Sein gehört-mit dem Denken- in das Selbe)" (69). Y ¿qué es ese "lo mismo" para el pensar no metafísico de Heidegger? Lo que da (es gibt) tanto al ser como al pensar su mismidad es su mutua pertenencia. Ahora, ese mutuo pertenecerse acontece, para Heidegger, como acontecimiento apropiante (Er-eignis) (91): en el Ereignis ${ }^{10}$, hombre y ser se pertenecen.

En suma, Heidegger, vislumbra junto con el comienzo tradicional de la filosofía como metafísica, cuya esencia gira en torno a la búsqueda de un fundamento (arkhé) absoluto que sea soporte de todo lo ente a partir del pathos de la admiración que produce lo real, otro comienzo del pensar cuyo sentimiento fundamental es el temor (Scheu), la serenidad (Gelasenheit) y el espanto (Schrecken) (Aportes 20-3). Otro comienzo, no uno nuevo, porque se ubica en otra parte y no después, en otro estrato en el que el tiempo histórico se ilumina a partir de la concepción del ser como acontecimiento apropiante (Ereignis). Este es un lugar en el que ya todos habitamos, pero del cual siempre alejamos la mirada. Este otro comienzo es el paso de la consideración de la metafísica como ontoteología a la del ser y la diferencia como acontecimiento apropiante (Ereignis); y el paso del pensamiento que interroga por el fundamento de lo real asegurándolo en la objetividad de la representación, al pensamiento que está a la escucha y contemplación del ser.

\section{El problema de la diferencia en el planteo deleuziano}

Deleuze, del mismo modo que Heidegger, denuncia que el problema de la irrupción de la diferencia ha sido despreciado y marginado de las reflexiones filosóficas occidentales, porque lo diferente vendría a representar al pecado, la falta o la caída en la tradición judeocristiana, o lo monstruoso o el enemigo en un contexto moral y político; en definitiva, la diferencia es identificada con todas aquellas fuerzas que representan el mal, lo extraño y lo peligroso. Así pues, llegados a este punto, Deleuze vuelve a plantear el problema que ya había mostrado Heidegger, i.e., por qué hay diferencia, y cómo pensar la diferencia en cuanto tal sin subsumirla en la identidad.

10 La noción de Ereignis puede ser traducida como acontecimiento apropiante, pero Heidegger afirma que esta palabra, como palabra conductora de su pensamiento, no se deja traducir al igual que el lógos griego. Ella remite, etimológicamente, a Er-auguen, que significa "asir con la mirada", "apropiarse" y "ser apropiado" a la vez. 
Para Deleuze, la fenomenología ${ }^{11}$ y la dialéctica no han sido capaces de pensar la diferencia debido a que ella se manifiesta como plena afirmación, sin ninguna referencia a un fundamento; pensar la diferencia implica no reducirla a una instancia superior, ni subsumirla o fundamentarla. En definitiva, el problema que claramente vuelve a actualizar el planteo deleuziano es: ¿cómo pensar una realidad que se efectúa y expresa como diferencia cuyos caracteres distintivos son el movimiento y la contingencia? ¿Cómo experimentar nuevos modos de pensamiento que rompan los presupuestos del pensamiento representativo que subordina siempre todas las expresiones diferentes a lo idéntico? Podemos adelantar aquí que esta experimentación es llevada adelante por Deleuze a partir de su tesis sobre la univocidad del ser. Esta tesis no significa que haya una primacía o una reducción a un principio o unidad que explique la univocidad del ser, tesis que sostiene el pensador francés Badiou en su libro sobre Deleuze (Cf. Badiou), sino que para Deleuze "lo esencial de la univocidad no es que el ser se diga en un solo y mismo sentido. Es que se diga, en un solo y mismo sentido de todas sus diferencias individuantes o modaliades intrínsecas" (Diferencia y repetición 72).

Entonces, Deleuze, del mismo modo que Heidegger, intenta elaborar una ontología de la diferencia en la que el ser sea liberado y desarraigado de su condición y estatus de fundamento de lo ente. El pensador francés presenta una nueva ontología en la que el ser es concebido como diferencia de diferencia, en cuanto que la diferencia es remitida a otras diferencias y no ya a la identidad del fundamento como principio totalizador. Como afirma Gallego: "Lo virtual no es ni lo posible ni lo probable sino, lo potencial, lo tenso, lo intenso, lo intensivo o, lo que es lo mismo, la diferencia considerada en tanto que ligada, conectada, referida a otras diferencias, aquello que tiende a hacer posible que la más alta potencia del ser, su más radical diversificación, nunca coincida con su disolución extrema" (16). En este sentido, de acuerdo a Deleuze, la diferencia debe ser considerada desde tres perspectivas: diferencial, diferenciante y diferenciada. La primera refiere a la esencia del ser, pero no a su esencia abstracta, sino que a su estado productivo, es decir, a su estado de potencia absoluta. La segunda muestra el estado tenso o intensivo de la diferencia, considerada en tanto conectada con otras diferencias; es aquella que hace que de la plena potencialidad (Cf. Gallego 16) ${ }^{12}$ se genere, produzca y potencie lo virtual. Por último, en tercer lugar, la diferencia diferenciada refiere a la dimensión en que las

11 Recordemos que Deleuze toma algunos elementos de la fenomenología de Husserl, a la vez que mantiene cierta distancia respecto de ella. Su acercamiento está dado por la recuperación de nociones husserlianas como la de "síntesis pasiva" o "empirismo trascendental", pero su distancia se debe a la incapacidad de sobrepasar el sentido común que debe dar cuenta de la identidad del objeto. Ello vuelve impotente a la fenomenología para pensar la diferencia en cuanto diferencia, puesto que no puede pensar las diferencias sin reducirlas a la identidad de una conciencia que las unifique.

12 Además, en la misma nota Gallego afirma que la noción de potencialidad debe comprenderse como el estado de tensión real de la relación existente entre dos o más diferencias, y no como posibilidad o probabilidad. Por su parte, la noción de potencia debe comprenderse como la capacidad de variación de una diferencia que no afecta sin ser afectada a la vez, y no como impulso, pulsión y acción subsidiarias, todas ellas, de la metafísica tradicional (16). 
diferencias ligadas se integran por regiones, es decir, en que la ligazón de las diferencias resuelve momentáneamente su constitutiva tensión alcanzando una estabilidad o actualidad provisoria que permite diferenciar unos simulacros ${ }^{13}$ de otros (Cf. 16). Desde este contexto ontológico que tiende a darle movilidad al ser, que concibe al ser como devenir y que hace del ser el ser del devenir; lo real es lo mutable y la realidad el resultado de la mutabilidad decidida por y en el seno de la diferencia considerada desde los tres elementos expuestos.

Sin embargo, al momento de pensarlo y expresarlo, todo ello queda reducido a las categorías propias de nuestras lenguas occidentales constituidas sobre la lógica de la identidad. Nuestras lenguas (occidentales) son lenguas metafísicas, lo que sugiere que apresan el devenir y la multiplicidad en estructuras estables para ponerlas a disponibilidad (objetividad). En este sentido, cabe aclarar que al afirmar "el ser es diferencia" o "el ser es devenir" estaríamos volviendo a pensar de acuerdo a la estructura de pensamiento propia de la metafísica occidental, porque en aquellas proposiciones se está identificando al ser con un ente determinado conforme a la lógica de la identidad. Por eso hemos optado por el genitivo para expresar y problematizar la diferencia, i.e., "diferencia de diferencia", dado que en este caso se presenta tanto la significación objetiva del genitivo como la subjetiva. De este modo, se le otorga movilidad al lenguaje y se evita referir la diferencia a algún centro unificador, fundamentante o totalizador. Con ello, la diferencia resulta móvil y logra fugarse por medio de la lógica de oposición metafísica.

Ahora bien, ¿a qué refiere Deleuze con la noción de medio? Es aquello que no tiene principio ni fin. El medio no es centro en el espacio; ni pasado, presente o futuro en el tiempo. Aquí no estamos hablando ni de evolución ni de historia. Una línea que pasa por medio de las oposiciones metafísicas supone la diferencia (línea de fuga $)^{14}$. Por ello, la fundamentación metafísica resulta inapropiada para comprender el carácter inmanente y eminentemente diferencial de la novedad. Para Deleuze, la filosofía de la diferencia y su íntima vinculación con la noción de medio puede ser caracterizada como rizomática:

Un rizoma no empieza ni acaba, siempre está en el medio, entre las cosas, inter-ser, intermezzo. El árbol es filiación, pero el rizoma tiene como tejido la conjunción “y... y... y.... En esta conjunción hay fuerza suficiente para sacudir y desenraizar el verbo ser. ¿Adónde vais? ¿De dónde partís? ¿Adónde queréis llegar? Todas estas preguntas son inútiles. Hacer tabla rasa, partir o repartir de

13 Fernando Gallego afirma que la noción de simulacro no refiere a cierta falta de realidad de lo real, sino que sirve para poner a un lado las contiendas metafísicas sobre las nociones de cosa, ente y objeto; de este modo, el simulacro refiere a la verdad de la realidad en un triple sentido: "1) porque se diferencia respecto de otros seres, 2) porque resulta diferenciado en el ser, 3) porque es, en sí mismo, bien una diferencia, bien la integración de un cierto complejo de diferencias mutuamente ligadas" (17).

14 Las líneas de fuga son líneas nómadas, creadoras de desterritorializaciones. Ellas escapan a todo dualismo rígido e inventan conexiones nuevas, imprevistas e imprevisibles. Son las líneas que propagan la diferencia. 
cero, buscar un principio o un fundamento, implican una falsa concepción del viaje y del movimiento (metódico, pedagógico, iniciático, simbólico...). [...] Entre las cosas no designa una relación localizable que va de la una a la otra y recíprocamente, sino una dirección perpendicular, un movimiento transversal que arrastra de la una a la otra, arroyo sin principio ni fin que socava las dos orillas y adquiere velocidad en el medio (Deleuze y Guattari 56-7).

Los acontecimientos, simbolizados por los rizomas, crecen y proliferan por todos lados, sin justificaciones últimas que permitan prever dónde crecerá el próximo rizoma, ya que siempre proliferan en medio o entre la maleza; ni en el centro justificador ni en la periferia justificada de la lógica metafísica, sino por medio o entre las oposiciones metafísicas. El medio o entre supone una constante tensión entre lo mismo y lo otro, entre el azar y la necesidad; ello impide el aseguramiento total de lo real dentro de categorías objetivadoras. Por otro lado, la noción de medio permite la creación de sentidos, admitiendo que no hay arkhé fundamental y último cuyo carácter de verdad sea incuestionable.

Por último, creemos que, tal como lo afirma Deleuze, la consecuencia más relevante de este planteo es sostener la posibilidad de hacer una filosofía antijerárquica, es decir, ningún ente "es" más que otro o, dicho de otro modo, ningún ente tiene una esencia que lo hace ser mejor que otro. No hay jerarquías sino coexistencias de cuerpos intensivos. Sostiene Deleuze en sus clases sobre Spinoza:

Lo que me parece impresionante en la ontología pura [spinoziana], es hasta qué punto repudia las jerarquías. [...] En el límite, es una especie de anarquía porque no existe ningún principio (arkhé) exterior y superior al ser. Hay una anarquía de los entes en el ser. Es la intuición básica de la ontología: todos los seres valen. La piedra, el insensato, el razonable, el animal, desde cierto punto de vista, desde el punto de vista del ser, valen. Cada uno es en tanto que es en sí, y el ser se dice en un solo y mismo sentido de la piedra, del hombre, del loco, del razonable. Es una bella idea. Una especie de mundo muy salvaje (En medio de Spinoza 44-5).

Clara es la construcción de una ontología antijerárquica y unívoca, dado que todo ente es un modo de ser, todo ente es en el mismo sentido de ser, pero esto no significa que el ser sea numéricamente uno sino que la univocidad refiere a la potencia del ser que se expresa en los diferentes entes. Pues el ser se dice en un solo y mismo sentido de la pluralidad de sus cuerpos o formas inmanentes en tanto expresan su infinita potencia (Badiou 43). Es decir, los entes remiten a un sistema de perfecta igualdad frente al ser, lo que implica un sistema abierto, i.e., la posibilidad infinita de una conexión o desconexión permanente de los elementos del sistema; produciendo una diferenciación siempre original y creativa, e impidiendo, a la vez, la posibilidad de una reducción de los elementos en una instancia absoluta y superadora. En definitiva, 
desde el punto de vista ontológico, no hay jerarquías; la univocidad del ser refiere a que, como afirma Deleuze, la piedra es, el insensato es, el razonable es, el animal es; ser se dice en un solo y único sentido de todos los entes. Pero, por otro lado, de aquí se deriva un gran problema que Deleuze señala: esta ontología ¿podría ser puesta en práctica en el campo político? Cuando Deleuze afirma: "Es una bella idea. Una especie de mundo muy salvaje”, está advirtiendo las dificultades que se derivan de esta posición para la práctica política, en el sentido de que no habría ningún criterio que permita ordenar la vida en común. Pero por ahora, dejemos este problema abierto y aboquémonos a entrecruzar las propuestas de pensamiento de Heidegger y Deleuze.

\section{La cuestión de la diferencia a partir de las filosofías de Heidegger y Deleuze}

Para Deleuze, la diferencia no puede ser pensada como un recuerdo o rememoración interna de la historia del pensamiento occidental, ni como la liberación del ser que debido a un olvido o error se ha extraviado en esta misma historia, tal como lo postularía Heidegger. Al respecto, Mengue sostiene que "la filosofía de la diferencia no puede consistir más que en una descripción de las relaciones de pura exterioridad que son constitutivas de lo múltiple como tal" (124). Así es que Deleuze considera que en la filosofía de Heidegger no se da una verdadera destrucción o superación de un modo de pensamiento regido por la lógica de la identidad y de las categorías metafísicas en general, porque se subordina la diferencia a la mismidad. Cabe preguntarse en primer lugar: ¿qué significa para Deleuze la subordinación de la diferencia a la mismidad? Como expusimos antes, para Heidegger, pensar la diferencia entre ser y ente implica pensar lo no pensado u olvidado en la noción de identidad, es decir, pensar la mismidad. Resulta claro, entonces, que para el pensador alemán pensar un ser sin telos, pensarlo como la nada, no como negación sino como aquello que se retrae y aparece al modo de ausencia en todo ente, escapa a la representación metafísica. En este punto podríamos encontrar un lugar de mutuo acuerdo entre ambos pensadores.

Con todo, el punto de desacuerdo fundamental entre uno y otro radica en que la diferencia heideggeriana se juega sobre lo mismo para todo el conjunto de los entes; es decir, Heidegger piensa la diferencia como orientada hacia el interior de cada ente como lo mismo. En este sentido, según la posición deleuziana, pensar lo impensado en la filosofía heideggeriana refiere a un pensamiento de la diferencia que debe cuestionar y pensar al ser y su diferencia con lo ente, pero sobre un mismo suelo que sostendría la relación diferencial, lo que conlleva seguir operando de acuerdo a la lógica de fundamentación. Por su parte, en el caso de la filosofía deleuziana ocurre todo lo contrario. No hay ni olvido de algo impensado e interno a los entes, ni un mismo suelo que sostenga la relación diferencial que constituya y haga la diferencia, 
sino que la diferencia se juega en el despliegue externo de lo múltiple en cuanto tal. Esta diferencia es producida a partir de la noción de repetición que Deleuze reelabora gracias a su lectura de la filosofía de Nietzsche. La repetición no es ni se juega sobre lo mismo, como se suele entender esta doctrina en Nietzsche, sino que la repetición es de lo que difiere, en cuanto que es una diferencia activa que diversifica lo ente en multiplicidades siempre nuevas y originales; y esta potencia activa es lo que se repite eternamente.

Para Deleuze, el movimiento del pensamiento heideggeriano, entonces, resulta de gran relevancia y un gran avance respecto a la destrucción de las categorías de fundamentación propias de la lógica metafísica, pero sostiene que ella queda a mitad de camino porque, en última instancia, la mismidad en la que se juega la relación ser-entes resulta ser nuevamente un centro unificador de fundamentación que ordena la realidad dentro de la misma lógica metafísica que se intentaba destruir o evitar. En definitiva, la postura deleuziana resulta taxativa respecto a la de Heidegger: postular una filosofía de la diferencia sobre la mismidad impide pensar y hacer la diferencia. La propuesta deleuziana se dirige a la posibilidad de una multiplicación diferenciante de las multiplicidades, en que la identidad del punto de partida nunca es conservada, ni subsumida, ni superada; lo que le interesa al pensador francés es pensar la realidad desde otra lógica, cuyo elemento irreductible sea la constitución heterogénica de lo real, según la cual lo múltiple no tenga nada en común, no tenga identidad alguna con su punto de partida. Esto impediría toda lógica de fundamentación o justificación regida por el principio de identidad como subyacente a las diferencias. Es decir, la potencia del ser que se expresa en las diferentes multiplicidades repite la diferencia eternamente como diferente a lo sido, a lo que es, y diferente también a lo que pueda ser. La potencia activa del ser, irreductible a la lógica de la identidad, que distribuye las diferencias multiplicándolas infinitamente, es la que retorna, pero siendo siempre diferente de sí misma.

Entonces, la diferencia está en la base de cualquier apertura del ser, de cualquier época histórica, dado que no hay historia sin una repetición original y originaria de la diferencia ser-ente; y a su vez, nuestra historia es la historia de la metafísica como repetición del olvido, del problema, que plantea la pregunta por la diferencia (Vattimo 77). Llegados a este punto, nos encontramos con ciertos equívocos en las interpretaciones de la filosofía heideggeriana, que quizás sean los mismos equívocos de la interpretación que realiza Deleuze. La diferencia ontológica es aquel carácter por el cual el ser se retrae al desentrañarse en el ente. La metafísica es consecuencia de ello como destino histórico del ser. Pero pensada así, la conexión entre ocultarsedesocultarse y destino parece ser una estructura objetiva que se sustrae a la diferencia como modo de apertura, eventual. Estas interpretaciones quieren hacer del ser del que habla Heidegger una estructura estable que se renueva al implicarse en la apertura y en la ocultación. Sin embargo, nosotros, que perseguimos la diferencia para problematizarla, no debemos caer en las estructuras objetivadoras de la metafísica para pensar por el medio, por donde la diferencia es diferencia móvil, acontecimiento 
apropiante que genera y destruye multiplicidades. Además, cuando Heidegger dice que la historia de la metafísica se produce por el olvido de la diferencia, no apunta solamente al hecho de que no se haya pensado al ser mismo, sino también al olvido de la diferencia como problema, al olvido de la problematización de la diferencia en su carácter contingente.

Resulta claro que Deleuze, del mismo modo que Heidegger, funda o si se quiere brinda nuevos aires al pensamiento filosófico a partir del cuestionamiento de la identidad, del concepto, de la representación, en favor de la diferencia, el devenir y la multiplicidad. Si hacer filosofía consiste en pensar al ser y al pensamiento en tanto que piensa al ser, ambos filósofos muestran que la diferencia está en la base de este nuevo modo de hacer filosofía. En contraposición a lo que numerosos pensadores y el mismo Deleuze afirma, nosotros sostenemos que en ambos filósofos hay una primacía de la diferencia por sobre la identidad, y que ambos autores también sostienen que la realidad del ser es diferir, pues tanto el sentido de Ereignis en la filosofía heideggeriana como la interpretación deleuziana de las nociones de diferencia y repetición remiten a una especie de posibilidad absoluta, a una condición de contingencia radical de la realidad que se brinda como apertura y donación, sin referencia a elementos trascendentales. Por otro lado, ambos pensadores hacen un gran esfuerzo por dejar de pensar metafísicamente la realidad, es decir, dejan de pensar binariamente o disyuntivamente lo que acontece, y para ello se valen de la noción de entre o medio. Esta noción mienta relaciones pero sin subsunciones ni superaciones, pues sugiere la apertura originaria del estallido de la diferencia como diferencia, el estallido del ser como afirmación de múltiples y diferentes fuerzas intensivas en relación (entes) o acontecimientos. Problematizar la diferencia en sí misma, como única instancia sobre la que se juega la contingencia de la realidad, sin necesidades trascendentales, supone superar la arquitectura categorial de la metafísica occidental.

Para finalizar, lo que hemos intentado en este artículo es hacer un análisis hermenéutico crítico para replantear el problema de la diferencia a partir de las filosofías de Deleuze y Heidegger, de manera que se sobrepujen mutuamente, evitando decidir o justificar a una por sobre la otra. Sobreponiéndolos y contrastándolos logramos pensarlos en conjunto, desde la indiscutible actualidad de sus filosofías, determinantes para comprender nuestro mundo y, a la vez, vehículo de un gran flujo de pensamiento para el futuro filosófico.

\section{Referencias}

Badiou, Alain. Deleuze. El clamor del ser. Buenos Aires: Manantial, 2002. Impreso. Deleuze, Gilles. Diferencia y Repetición. Buenos Aires: Amorrortu, 2002. Impreso. ---. En medio de Spinoza. Buenos Aires: Cactus, 2008. Impreso.

Deleuze, Gilles y Felix Guattari. Rizoma. Valencia: Pre-Textos, 2003. Impreso. 
Esperón, Juan Pablo. "Metafísica y post-filosofía en el pensamiento de Martin Heidegger”. RiHumSo. Revista de Investigación del Departamento de Humanidades y Ciencias Sociales 1.4 (2013): 62-96. Impreso.

Gallego, Fernando. "Prefacio a un libro necesario". Deleuze o el sistema de lo múltiple. Philippe Mengue. Buenos Aires: Las cuarenta, 2008. 5-48. Impreso.

Heidegger, Martin. Identidad y Diferencia. Barcelona: Anthropos, 1990. Impreso.

---. "La esencia del fundamento". Hitos. Madrid: Alianza, 2000. 109-149. Impreso.

---. Aportes a la Filosofía. Acerca del Evento. Buenos Aires: Biblos, 2009. Impreso.

Mengue, Philippe. Deleuze o el sistema de lo múltiple. Buenos Aires: Las cuarenta, 2008. Impreso.

Vattimo, Gianni. Las aventuras de la diferencia. Barcelona: Península, 1986. Impreso.

Recibido: 22 julio 2014

Aceptado: 07 octubre 2015 